University of Nebraska - Lincoln

DigitalCommons@University of Nebraska - Lincoln

\title{
Effects of drought, temperature, herbivory, and genotype on plant-insect interactions in soybean (Glycine max)
}

\author{
Rose Grinnan \\ North Carolina State University \\ Thomas E. Carter Jr. \\ USDA-ARS, Thomas.Carter@ars.usda.gov \\ Marc T. J. Johnson \\ University of Toronto at Mississauga, marc.johnson@utoronto.ca
}

Follow this and additional works at: https://digitalcommons.unl.edu/usdaarsfacpub

Grinnan, Rose; Carter, Thomas E. Jr.; and Johnson, Marc T. J., "Effects of drought, temperature, herbivory, and genotype on plant-insect interactions in soybean (Glycine max)" (2013). Publications from USDAARS / UNL Faculty. 1253.

https://digitalcommons.unl.edu/usdaarsfacpub/1253

This Article is brought to you for free and open access by the U.S. Department of Agriculture: Agricultural Research Service, Lincoln, Nebraska at DigitalCommons@University of Nebraska - Lincoln. It has been accepted for inclusion in Publications from USDA-ARS / UNL Faculty by an authorized administrator of DigitalCommons@University of Nebraska - Lincoln. 


\title{
Effects of drought, temperature, herbivory, and genotype on plant-insect interactions in soybean (Glycine max)
}

\author{
Rose Grinnan • Thomas E. Carter Jr. • \\ Marc T. J. Johnson
}

This article is a U.S. government work, and is not subject to copyright in the United States.

Received: 18 April 2012/ Accepted: 31 October 2012/Published online: 18 November 2012

(C) Springer Science+Business Media Dordrecht 2012

\begin{abstract}
Climate change is predicted to cause continued increases in global temperatures, greater variability in precipitation and in some cases, more frequent insect pest outbreaks. Here we seek to understand how abiotic and biotic stresses associated with climate change can affect plant-herbivore interactions in a model crop species (soybean, Glycine $\max (\mathrm{L}$.) Merr.) by answering three questions: (1) Do the combined effects of abiotic and biotic stresses associated with climate change cause synergistic negative effects on plant biomass? (2) Can abiotic stress affect resistance of plants to insect herbivores? (3) Does genetic variation in plant traits modify a plant's response to stress? We performed three experiments in controlled growth environments using up to 51 soybean genotypes selected to vary in numerous traits associated with drought and resistance against pests (e.g., insect herbivores, nematodes, and pathogenic fungi), and up to 3 generalistfeeding herbivorous noctuid moth species (Helicoverpa zea, Heliothis virescens, and Spodoptera exigua) that commonly feed on soybean in North America. Drought and
\end{abstract}

Handling Editor: Michael Smith.

Electronic supplementary material The online version of this article (doi:10.1007/s11829-012-9234-z) contains supplementary material, which is available to authorized users.

\section{R. Grinnan}

Department of Plant Biology, North Carolina State University, Raleigh, NC, USA

T. E. Carter Jr.

USDA-ARS, Raleigh, NC, USA

M. T. J. Johnson $(\square)$

Department of Biology, University of Toronto at Mississauga,

Mississauga, ON, Canada

e-mail: marc.johnson@utoronto.ca herbivory had the largest and the most consistent negative effects on plant performance, reducing the above- and below-ground biomass by $10-45 \%$, whereas increased temperature had little to no effect on plants. Drought also increased susceptibility to generalist noctuid herbivores, but these results varied dramatically in magnitude and direction among plant genotypes. Our experiments show that the effects of abiotic and biotic stress on soybean biomass were largely due to the additive effects of these stresses, and there exists substantial genetic variation in the soybean germplasm pool we studied that could be used as a source of parental stock in breeding new crops that can more effectively tolerate and resist the combined negative effects of insect herbivory and drought.

Keywords Herbivore resistance - Legume - Plant defense Plant stress hypothesis - Pulsed stress hypothesis .

Wilt avoidance

\section{Introduction}

Earth's climate is rapidly changing and most climate models predict continued increases in temperature and greater variability in precipitation (IPCC 2007). The effects of these changes on communities and ecosystems are less certain, although it is widely believed that ongoing environmental change could profoundly alter the ecology and evolution of species' populations (Parmesan 2006; Williams and Jackson 2007; Tylianakis et al. 2008; Hoffmann and Sgro 2011). For example, increased temperatures over the last several decades are correlated with shifts in species' phenology (Walther et al. 2002; Willis et al. 2008), altered range distributions (Parmesan 2006; Kelly and Goulden 2008), and changes in species' abundances and 
interactions (Roy et al. 2004; Adams et al. 2009; O'Connor 2009; van Mantgem et al. 2009). Here we seek to disentangle some of this complexity using multifactor experiments that examine how drought, temperature, herbivory, and plant genotype could simultaneously influence plantherbivore interactions in a model agricultural species.

Increases in temperature and drought may facilitate corresponding increases in the frequency and severity of insect population outbreaks (Logan et al. 2003; Rouault et al. 2006; Easterling et al. 2007; Paritsis and Veblen 2011). The Plant Stress Hypothesis predicts that environmental stress increases a plant's susceptibility to insect herbivory by altering leaf chemistry and whole plant physiology (White 1984; Koricheva et al. 1998). Specifically, abiotic stress can cause a reduction in plant defense compounds and an increase in available nitrogen and digestible proteins relative to carbon availability, leading to more palatable food for some insect herbivores (White 1984; Huberty and Denno 2004; White 2009; Gutbrodt et al. 2011). Thus, the compounded effects of environmental stress and increased population outbreaks could lead to non-additive synergistic reductions in plant performance in natural and managed ecosystems (Logan et al. 2003). Conversely, drought can lead to increased concentrations of the secondary metabolites in some plant species (Hale et al. 2005), and effects on herbivore performance can vary according to taxonomy and feeding behavior of insect species (Huberty and Denno 2004; Mody et al. 2009; White 2009). It is, therefore, important to understand how environmental factors influence plant-herbivore interactions from the perspective of both the plant and the herbivore.

The predicted changes in the biotic and abiotic environments associated with climate change could have large negative effects in agricultural systems (Battisti and Naylor 2009; Long and Ort 2010; Sinclair 2011). Many studies have investigated how crops respond to predicted changes in abiotic stress factors such as drought, temperature, or atmospheric gas concentrations (English-Loeb et al. 1997; Daane and Williams 2003; Easterling et al. 2007; Zavala et al. 2008; Battisti and Naylor 2009; Mody et al. 2009; Gutbrodt et al. 2011; White et al. 2011). Comparatively fewer studies have examined the potential interactive effects of abiotic and biotic stress factors on plant performance in agricultural or natural systems (Hawkes and Sullivan 2001; Hale et al. 2005; Olson et al. 2009). For two major abiotic and biotic stress factors, drought and herbivory, this knowledge gap is critical. Understanding whether the combined effects of drought and herbivory lead to synergistic negative effects on plants or independent negative effects is essential to predict the potential impacts of climate change (Darling and Cote 2008). Such knowledge is especially important in agriculture where climate change could threaten sustainable food production (Battisti and Naylor 2009; Long and Ort 2010).

Most crops are composed of a diverse array of varieties that exhibit variation in ecologically important traits (Matson et al. 1997). These traits include tolerance to drought and other abiotic stresses, resistance to pests, increased yield potential, and improved nutritional content (Sinclair 2011). As a result, many varieties may already possess some ability to withstand environmental change as well as herbivorous insect outbreaks. Despite important advances in plant breeding, in many cases we do not know the durability or stability of these advances over a wide range of environmental factors associated with climate change. Therefore, it is necessary to identify genotypes, traits, and genes which most effectively impart robust resistance and tolerance to environmental stresses associated with climate change (Sinclair 2011).

Here we seek to understand how the combined effects of drought, increased temperature, herbivory, and plant genotype can affect plant-herbivore interactions in a model crop system, soybean (Glycine max (L.) Merr.). In order to address this goal we conducted three experiments in controlled environments to answer the following questions: (1) How do the combined effects of drought, temperature, and herbivory affect plant performance, quantified here as allocation to the above- and below-ground biomass? (2) Do drought or temperature affect a plant's resistance to insect herbivores? (3) Do plant genotypes vary in their response to abiotic stress and resistance to insect herbivores, and are such responses genetically correlated? Our results and conclusions provide insight into how multiple environmental factors associated with climate change can simultaneously influence a model crop species.

\section{Materials and methods}

\section{Study system}

Soybean is a member of the Fabaceae family and is a leguminous herbaceous crop of global importance, with an estimated yield of 258 million metric tons and $\$ 39$ billion in sales in 2010 alone (American Soybean Association 2010). Soybean varieties have been bred for a diverse array of phenotypic traits, including increased resistance to drought and herbivory (Carter et al. 2004). For these reasons, soybean represents an important model for understanding the effects of environmental stresses associated with climate change on plant-herbivore interactions in agricultural systems.

In order to capture the breadth of genetic diversity available in soybean as parental stock for varietal development through plant breeding, we used 51 genotypes 
representing a wide range of insect resistance, drought resistance in the form of delayed canopy wilting, and zone of adaptation (see Online Supplemental Material, Supplemental Table 1). Zone of adaptation in these genotypes ranged from Nebraska to Georgia in the USA, and was quantified as "maturity group," a categorical descriptor of development time and photoperiod response where each ascending number indicates an approximate 1 week delay in harvest maturity under natural day length (Fehr and Caviness 1977; Supplemental Table 1); our maturity groups ranged from II to VII.

We used three agricultural Lepidopteran pest insects in the Noctuidae, all common on soybean in the southeastern USA (Kogan and Kuhlman 1987; Micinski et al. 2008). These insects included Heliothis virescens Fabricius (Noctuidae), the tobacco earworm; Helicoverpa zea Boddie (Noctuidae), the corn earworm; and Spodoptera exigua Hübner (Noctuidae), the beet armyworm. All three species are generalist feeders, meaning that they feed on soybean and many other plant species from other plant families.

\section{Experimental procedures}

In order to understand the combined effects of drought, temperature, herbivory, and plant genotype on plant and insect performance, we conducted three experiments in controlled environmental conditions. Plant performance was quantified as allocation to the above- and belowground biomass. Biomass is one of the most commonly used measures of plant performance in ecological studies (Hawkes and Sullivan 2001; Geber and Griffen 2003; Leimu and Koricheva 2006b), and it is typically highly correlated with multiple components of plant fitness (Hawkes and Sullivan 2001), including in soybean (Shimada et al. 1992; Cox and Cherney 2011). Although an important measure of crop performance, we did not measure seed yield because of the wide range in phenology (maturity groups II through VII) in the genotypes under study, which would be expected to have a 5 weeks range in maturity. Such large differences in maturity can confound and overwhelm treatment effects (Hartwig 1973). The potential for confounding from phenological effects was minimized by growing plants under a sufficiently long light period such that pod filling was effectively delayed until after the termination of the experiments. Also, the use of pots can induce root binding when soybean is grown to maturity, making seed yield results open to interpretation. Insect performance was measured as a gain in mass from freshly hatched neonate caterpillars until they were 7 days old (Glynn et al. 2004; Hale et al. 2005; Johnson and Agrawal 2005; Campitelli et al. 2008; Mody et al. 2009). The gain in insect mass during the first instars of growth correlates with insect survival (Johnson et al. 2009) and is one of the most commonly used measures of plant resistance against insects (Leimu and Koricheva 2006a; Carmona et al. 2011). We describe the detailed methods used for each of these experiments below.

Experiment 1: effects of drought and herbivory on plant performance

In order to address question 1 , we tested the combined effects of drought and herbivory on the above- and belowground biomass of soybean using a factorial design. We conducted the experiment in a greenhouse at North Carolina State University during summer 2009 using the soybean variety "NC-Roy" (Burton and Carter 2005), a popular conventional variety grown in North Carolina. Eighty plants were grown in round clay pots $(1,650 \mathrm{ml}$, $15 \mathrm{~cm}$ diameter), with a $1: 1 \mathrm{mix}$ of steam sterilized sand and topsoil. Plants were fertilized 6 days after seeds were sown with $4.2 \mathrm{~g}$ of Osmocote slow-release fertilizer pellets (14-14-14, N-P-K; The Scotts Co., Marysville, OH, USA) dispersed on the soil surface, and 11-12 $\mathrm{ml}$ of micronutrient fertilizer $(8 \mathrm{mg} / \mathrm{L}$ water; Scotts Peters Professional STEM Fertilizer, The Scotts Co., Marysville, OH, USA).

We initiated drought treatments at a standard plant developmental stage and terminated drought based on observed plant wilting. Specifically, we initiated drought to a random half of plants by withholding water when the $3 \mathrm{rd}$ to 4th trifoliate leaf of plants were fully expanded, which corresponded to 18 days after planting. Plants were assessed for drought response daily and each plant was "rescued" by watering when $>90 \%$ of leaves lost turgor and the apical meristem wilted to an angle $>45^{\circ}$ to the vertical axis. Given these criteria, "Drought treated" plants were subject to stress for an average of 4.2 days (range: 3-5 days) and they received water daily for the remainder of the experiment. This type of drought treatment was termed a "pulsed drought" by Huberty and Denno (2004), which they argue is more representative of natural conditions than experimentally imposed continuous droughts.

We added herbivorous insects to plants shortly after the end of the drought treatment, as opposed to during the drought, because the positive or negative effects of drought on insect herbivores are expected to be the greatest when plants are recovering from water stress (White 1984; Huberty and Denno 2004). We tried to simulate the effects of a pest outbreak to match those predicted to become more frequent with climate change (IPCC 2007). Specifically, 26 days after planting, herbivory was imposed on a random half of both the previously drought-treated and control plants by placing the $3 \mathrm{rd}$ instar $H$. virescens caterpillars (F. Gould Lab, Dept of Entomology, NC State University) 
directly onto plants enclosed in white polyester tulle. We used $H$. virescens to impose damage to plants in experiments 1 and 2 because it a common pest of soybean (Turnipseed and Kogan 1976; Kogan and Turnipseed 1987), it quickly removes the target amount of tissue and we had a large colony on site. We visually estimated percent herbivory on each leaf of the plant to the nearest $5 \%$ and subsequently removed herbivores from a plant when caterpillars consumed $25-30 \%$ of the leaf tissue (mean damage $\pm 1 \mathrm{SE}=25.3 \pm 2.3 \%, n=40$ plants) on an entire plant. This amount of herbivory is representative of the amount of tissue removed by chewing insect herbivores during a modest outbreak in the field (Turnipseed and Kogan 1976; McPherson et al. 2001). The number of caterpillars added to plants varied depending on the rate of damage, and caterpillars were moved between plants to ensure that plants received the same amount of damage over a short period of time.

We harvested the above- and below-ground biomass of each plant 2.5 weeks following the removal of insects (days 48 and 49). The above- and below-ground tissues were dried at $38{ }^{\circ} \mathrm{C}$ for 3 days and weighed. Shoot:root ratio was calculated for each plant.

The effects of drought and herbivory on soybean biomass were analyzed as a two-factor analysis of variance (ANOVA) using the model: Biomass $=$ Mean $_{\text {overall }}+$ Drought + Herbivory + Drought $\times$ Herbivory + Error. We examined the residuals of the untransformed data for each variable separately to determine whether assumptions of homogeneity of variance and normality were met; assumptions were met for all but below-ground biomass, for which we used a squareroot transformation. All treatment factors were treated as fixed effects and analyses were performed in PROC GLM in SAS (SAS Institute Inc. 2009).

Experiment 2: effects of drought, temperature, and herbivory on plant performance

In order to further understand the combined effects of drought, temperature, and herbivory on soybean performance (question 1), we conducted a factorial experiment using custom-made reach-in growth chambers at NC State University phytotron in 2009 and 2010, which provided precise control over temperature and lighting. We used a total of eight "C-chambers" $\left(1.1 \mathrm{~m}^{2}\right.$ growing area; $1,760 \mathrm{~W}$ fluorescent lamps plus $600 \mathrm{~W}$ incandescent lamps), which allowed us to achieve a light intensity of $450 \mu \mathrm{mol} \mathrm{m}{ }^{-2} \mathrm{~s}^{-1}$. Each chamber held twelve pots with one plant grown per pot, using the variety NC-Roy. The experiment was staggered over three trials as we could not use all chambers simultaneously; each trial included ambient and increased temperature chambers. We set chambers to a $13.5: 9.5 \mathrm{~h}$ light:dark cycle (equivalent to photoperiod in June in southeastern USA) with two $30 \mathrm{~min}$ transition periods to simulate sunrise and sunset.

Our manipulation of light and temperature was designed to mimic ambient conditions in the early growing season of soybean, and also included a temperature treatment that slightly exceeded the $2{ }^{\circ} \mathrm{C}$ target threshold for global temperature increase proposed at the Copenhagen Accord and adopted by the United Nations (UN) and European Union (EU) (UNFCCC 2009). The early growing season (June) was chosen because (1) the stage of growth exhibited by our plants was the most similar to local field soybean at that time of year, and (2) because this is the month in which a recent study showed the strongest correlation between increased temperatures and decreased precipitation in the USA during the past 80 years (Portmann et al. 2009). These treatments were applied by setting the temperature of 4 chambers to a $28.9{ }^{\circ} \mathrm{C}: 16.1{ }^{\circ} \mathrm{C}$ (ambient) day:night cycle, and the other 4 chambers to $31.1{ }^{\circ} \mathrm{C}: 18.3{ }^{\circ} \mathrm{C}\left(2.2{ }^{\circ} \mathrm{C}\right.$ increase $)$ day:night regime. The mean relative humidity in the chambers was measured at 28 and $26 \%$ in ambient and increased temperature chambers, respectively.

Soybean seed were planted in round plastic pots $(1,650 \mathrm{ml}, 15 \mathrm{~cm}$ diameter) with a 1:1 mixture of sterilized sand and soil. Within 7 days of planting, we added $2.5 \mathrm{~g}$ of Osmocote (14-14-14, N-P-K) slow-release fertilizer pellets to the soil surface and micronutrient fertilizer as described in Experiment 1.

Drought was initiated and ended using the same standardized criteria of plant developmental stage and phenotypic indicators of water stress as in Experiment 1. Since the plants grew more slowly in the growth chambers than in the greenhouse, the duration of experiment 2 was longer than experiment 1 . Specifically, drought was induced on day 20 after planting by withholding water from a randomly chosen half of the plants. We relieved the drought using the same criterion used for Experiment 1, and we maintained a daily watering schedule thereafter. Plants were drought-treated for an average of 8.8 days (range: 6-11 days).

Herbivory was imposed shortly after the cessation of drought following the same rationale as in experiment 1 . We placed the 3rd instar Heliothis virescens onto one-half of soybean plants on days 36-41, depending on the length of drought within the trial. We again removed caterpillars when the targeted $25-30 \%$ of leaf tissue was removed (mean $=30.0 \pm 1.2 \%)$. All plants were isolated in bags constructed of white polyester Organza fabric (Casa Collection, New York City, NY, USA) which we removed at the end of the herbivory period (average: 5 days of herbivory; range: 3-9 days) so that the use of bags would have minimal effect on plant growth. Plants were allowed to resume normal growth for 1 week before harvest, which occurred between days 46 and 56, depending on the length of drought and herbivory 
within each trial. The above- and below-ground biomass were harvested, dried, and weighed as in Experiment 1.

Analysis of Experiment 2 required a more complex statistical model. The unit of replication varied among the three main treatment factors: The unit of replication for the Temperature treatment was the individual chamber, whereas the unit of replication for the Drought and Herbivory treatments was each plant. In order to increase our replication of the number of independent replicates of the Temperature treatment, we conducted multiple experimental trials, repeating the same experimental design each time. The "full model" for all analyses was as follows: Biomass $=$ Mean $_{\text {overall }}+$ Trial + Temperature + Trial $\times$ Temperature + Chamber(Temperature $)+$ Drought + Herbivory + Trial $\times$ Drought + Trial $\times$ Herbivory + Temperature $\times$ Drought + Temperature $\times$ Herbivory + Temperature $\times$ Drought $\times$ Herbivory + Error. All effects in italics were treated as random effects and appropriate denominator terms and degrees of freedom were determined using the "test" statement in PROC GLM in SAS. In order to decrease the parameterization of the model and to increase statistical power, we removed non-significant interactions (cut-off $P>0.15$ ) and blocking effects (trial and chamber) by a backwards sequential stepwise procedure. We applied this procedure to each performance variable separately by starting at the highest-order interaction term. We continued the backwards removal of parameters until we reached the "reduced model" shown in Table 3; simpler interactions and main effects were retained when higher order interactions containing the simpler terms were found to be significant, according to our criterion. Residuals were examined for homogeneity of variance and normality, which determined that all variables met assumptions of ANOVA, except shoot:root ratio, for which we applied a log-transformation.

Experiment 3: effects of drought, temperature, and plant genotype on plant performance and resistance to herbivores

In order to determine the impact of drought on herbivore performance and, thus, resistance to herbivores (question 2 ), as well as genetic variation in response to drought and resistance to insects (question 3), we conducted a Drought $\times$ Genotype factorial experiment. The motivation for this experiment was to understand whether our results from Experiments 1 and 2 were consistent among a diverse array of soybean varieties, and to understand whether there existed plant genotypes that were simultaneously resistant to drought and to common herbivorous insects of soybean. The experiment was conducted in the same greenhouse as Experiment 1 during the summer of 2009. The experiment used 51 soybean genotypes (Online Supplemental Table 1) with 10 replicate plants per genotype for a total of 510 plants, where plants and treatments were completely randomized. Soybean seed were planted as described in Experiment 1 with the exception of using a 1:1 mix of sterile sand and a germinating soil mixture.

In order to examine the effects of temperature on plants, we used an existing temperature gradient in the greenhouse. We characterized this gradient using five Extech ${ }^{\circledR}$ Instruments TH10 Temperature Dataloggers (Extech Instruments Corp., Waltham, MA, USA) evenly spaced along the length of the bench. The average day and night temperatures during this time were 30.1 and $25.8^{\circ} \mathrm{C}$, respectively, with a $3{ }^{\circ} \mathrm{C}$ linear gradient along the length of the greenhouse bench, created by the effects of an evaporative cooler at one end of the greenhouse. Plants were allowed to experience ambient day:night light cycles because the experiment was conducted in a greenhouse during long days in July and early-August.

We applied the initiation and cessation of drought using the same standardized criteria as in experiments 1 and 2 . We imposed drought to half of the replicates ( 5 plants from each genotype) from each genotype at the 3rd to 4th true leaf development stage described in experiments 1 and 2, which corresponded to 24 days after planting. We scored wilt daily and ended the drought when a plant exhibited the wilting phenotype described in experiment 1. Plants experienced drought for an average of 11 days (range: 3-15 days), and this varied between plants and from previous experiments because we only watered plants once they exhibited the same wilting phenotype used for the first two experiments. Once a plant exhibited this wilting phenotype we watered the plant daily until harvest. The ability for a plant to avoid wilting may provide an important physiological mechanism to mitigate negative effects of drought (Charlson et al. 2009). We, therefore, quantified wilt avoidance as the number of days it took a plant to reach the critical wilt stage at which we watered plants.

In order to determine how drought, temperature, and plant genotype influence a plant's resistance to insect herbivores, we used detached leaf no-choice bioassays of caterpillar growth on leaf disks as described in Johnson et al. (2009). Such bioassays provide a highly repeatable and standardized high-throughput method for assaying resistance of plants to herbivores, especially in their earliest larval stages when insects are the most susceptible to a plant's defenses yet are difficult to track on live plants (Glynn et al. 2004; Hale et al. 2005; Campitelli et al. 2008; Mody et al. 2009). Moreover, petri-dish bioassays from lab experiments are frequently well correlated with bioassays measured on whole plants (Glynn et al. 2004) and with measures of resistance in the field (Johnson et al. 2009), even though systemic induced responses following damage are impaired in detached leaf assays (Karban and Baldwin 1997). We performed bioassays shortly after the cessation of drought (day 41 of the experiment), to assess the 
resistance of all plants to three common agricultural insect pests of soybean (H. virescens, H. Zea, S. exigua). Three round holes $\left(11.34 \mathrm{~cm}^{2}\right)$ were punched from the 2nd fully expanded trifoliate leaf below the primary apical meristem of each plant with a Marvy Uchida LVEJCP craft punch (Uchida of America, Torrance, CA, USA). Leaf punches were placed individually into $60 \times 15 \mathrm{~mm}$ polystyrene petri dishes lined with moistened filter paper. Newly hatched caterpillars of $H$. virescens, $H$. zea, and $S$. exigua ordered from Benzon Research (Carlisle, PA, USA) were placed individually on punched leaves, such that we assayed resistance of each plant to all three insect species, with 10 replicate plants per genotype distributed equally between drought and non-drought treatments. The insects were allowed to feed on a leaf punch in the petri dish for 1 week, at which point the insects were removed and placed in $1.5 \mathrm{ml}$ centrifuge tubes. They were allowed to void their gut contents for ca. $24 \mathrm{~h}$ and were then frozen until weighing. We measured the wet mass of insects (in $\mathrm{mg}$ ) as a measure of plant resistance (less mass corresponded to greater resistance exhibited by the plant) on a Mettler AT20 FACT microbalance digital scale (MettlerToledo, Columbus, OH, USA).

Plant growth rate was measured as the daily increase in plant height of each plant during the first 3 weeks of growth following germination. On day 59, we harvested the aboveground biomass from all soybean plants by cutting plants at the soil surface and placing them in a paper bag. The bags were dried at $38{ }^{\circ} \mathrm{C}$ and weighed as in Experiment 1.

We analyzed these data using restricted maximum likelihood (REML) in Proc Mixed in SAS because of the complex mixed model design (Littell et al. 1996; Fry 2004; SAS Institute Inc.). These analyses employed the following full model: Plant Biomass (or Insect Biomass) $=$ Mean $_{\text {overall }}+$ Drought + Temperature + Maturity Group + Genotype $($ Mat.Grp. $)+$ Drought $\times$ Temperature + Drought $\times$ Maturity Group + Drought $\times$ Genotype (Mat. Grp) + Temperature $\times$ Maturity Group + Temperature $\times$ Genotype(Mat. Grp.) + Drought $\times$ Temperature $\times$ Maturity Group + Drought $\times$ Temperature $\times$ Genotype (Mat. Grp. $)+$ Error. Temperature varied continuously among plants and was treated as a covariate in analyses. Factors in italics were all treated as random effects and their significance was tested using log-likelihood ratio tests based on the comparison of $-2 \times$ restricted $\log$-likelihood of nested models, fit to a $\chi^{2}$ distribution with 1 degree-of-freedom (Littell et al. 1996; Agrawal et al. 2002). All other effects were treated as fixed and their significance was assessed using $F$ tests and the appropriate degrees of freedom. As with Experiment 2, we reduced the complexity of models using a backwards stepwise selection procedure and assessed whether our residuals met assumptions of homogenous variance and normality.
In order to identify genetically variable plant traits correlated with plant and insect responses, we estimated the genetic variance for phenotypic traits and calculated genotype means using the raw untransformed data using PROC GLM. We then calculated Pearson Product Moment correlation coefficients based on the genotypic means and their corresponding $P$ values.

\section{Results}

Experiment 1: effects of drought and herbivory on plant performance

Drought and herbivory had strong independent negative effects on all measures of plant biomass, including the above-ground, the below-ground, and the total biomass (Table 1). Specifically, drought reduced the above- and below-ground biomass by 24 and $10 \%$, respectively, while herbivory reduced the same measures of performance by 20 and $19 \%$, respectively (Fig. 1a, b). Drought and herbivory exhibited a weak non-significant interaction that affected the

Table 1 Analysis of variance results from Experiment 1 showing the effects of drought and herbivory on plant performance

\begin{tabular}{|c|c|c|c|c|}
\hline & $d f$ & SS & $F$ & $P$ \\
\hline \multicolumn{5}{|c|}{ Total biomass } \\
\hline Model & 3 & 193.42 & 17.50 & $<0.001$ \\
\hline Drought & 1 & 84.52 & 22.94 & $<0.001$ \\
\hline Herbivory & 1 & 104.67 & 28.40 & $<0.001$ \\
\hline $\mathrm{D} \times \mathrm{H}$ & 1 & 7.98 & 2.16 & 0.15 \\
\hline Error & 75 & 276.39 & & \\
\hline \multicolumn{5}{|c|}{ Below-ground biomass (square-root transformed) } \\
\hline Model & 3 & 2.62 & 10.01 & $<0.001$ \\
\hline Drought & 1 & 0.51 & 5.89 & 0.018 \\
\hline Herbivory & 1 & 2.13 & 24.45 & $<0.001$ \\
\hline $\mathrm{D} \times \mathrm{H}$ & 1 & 0.001 & 0.01 & 0.92 \\
\hline Error & 75 & 6.55 & & \\
\hline \multicolumn{5}{|c|}{ Above-ground biomass } \\
\hline Model & 3 & 85.85 & 16.78 & $<0.001$ \\
\hline Drought & 1 & 48.19 & 28.26 & $<0.001$ \\
\hline Herbivory & 1 & 33.66 & 19.75 & $<0.001$ \\
\hline $\mathrm{D} \times \mathrm{H}$ & 1 & 5.79 & 5.79 & 0.069 \\
\hline Error & 75 & 127.86 & & \\
\hline \multicolumn{5}{|c|}{ Above-ground: below-ground biomass ratio } \\
\hline Model & 3 & 6.85 & 4.18 & 0.009 \\
\hline Drought & 1 & 0.26 & 0.47 & 0.49 \\
\hline Herbivory & 1 & 5.60 & 10.26 & 0.002 \\
\hline $\mathrm{D} \times \mathrm{H}$ & 1 & 0.91 & 1.67 & 0.20 \\
\hline Error & 75 & 40.95 & & \\
\hline
\end{tabular}

Any transformations applied to the data to meet assumptions of ANOVA are shown in parentheses 
above-ground biomass $(P=0.069)$, which was caused by smaller negative effects of herbivory on drought-treated plants compared to control plants (Fig. 1a). No other component of plant biomass exhibited such an interaction (all $P \geq 0.15$ ) (Fig. 1; Table 1). Therefore, the abiotic and biotic stressors manipulated in this experiment had no clear synergistic negative effect on allocation to plant biomass. Drought and herbivory did differentially affect the relative allocation to the above-ground and the below-ground biomass, such that drought had no significant effect on the ratio of the above- to below-ground biomass (Table 1), while herbivory caused a $23 \%$ increase in the ratio (Fig. 1c).

Experiment 2: effects of drought, temperature, and herbivory on plant performance

The use of growth chambers allowed us to simultaneously manipulate and test the combined effects of drought, herbivory, and temperature on plant performance. Consistent with Experiment 1, drought and herbivory reduced most components of plant biomass (Online Supplemental Fig. 1; Table 2). In experiment 2, the average reduction in biomass due to drought (43-45\%) was larger than the effect of herbivory (12-13\% reduction) (Online Supplemental Fig. 1; Table 2), even though herbivores removed slightly more tissue in this experiment $(30 \%)$ compared to the previous experiment $(25 \%)$. Increased temperature had neither discernible effect on the above-ground or the below-ground biomass $(P>0.45$ for all main effects of temperature; Table 2), nor did this factor show any clear interactions with either drought $(P \geq 0.13)$ or herbivory $(P \geq 0.39)$, so these interactions were removed from the final statistical models as described in the "Materials and Methods."

As with Experiment 1, drought and herbivory showed weak non-significant interactions that affected the aboveground biomass $(P=0.066$, Table 2$)$ and shoot:root ratio $(P=0.074)$. In both cases, interactions resulted from weaker effects of herbivory on drought-treated plants compared to control plants. Drought and herbivory did not interact to affect the total biomass $(P=0.12)$ or the belowground biomass $(P=0.43)$. Thus, if there is an interaction between stressors that does affect plant biomass, it is nonsynergistic and it is very weak compared to the main effects of these stressors (Table 2).

The effect of drought and herbivory on the ratio of the above- to below-ground biomass was inconsistent with Experiment 1. In Experiment 2, drought and herbivory significantly reduced the ratio by $3.5 \% \quad(F=0.74$, $P=0.48)$ and $9.5 \%(F=24.56, P<0.001)$, respectively (Online Supplemental Fig. 1); whereas herbivory caused the ratio to increase in Experiment 1 (Fig. 1c).
Experiment 3: effects of drought, temperature, and plant genotype on plant performance and resistance to herbivores

\section{Plant biomass and wilt avoidance}

As with the previous experiments, drought significantly reduced the above-ground biomass ( $37 \%$ reduction), while temperature had no direct independent effect on plant biomass (Table 3). There was, however, a significant interaction between drought and temperature that was associated with a negative effect of higher temperatures on plant biomass in non-drought plants, but no effect of increased temperature was observed when plants were subjected to drought (Fig. 2).

Soybean genotypes varied in the above-ground biomass by $90 \%$ from the smallest to the largest genotype, and this effect was not dependent on either drought (Genotype $\times$ Drought: $P=0.38$ ) or temperature (Genotype $\times$ Temperature, $P=0.5)$. The lack of an interaction reveals that the 51 soybean genotypes did not express genetic variation for their ability to tolerate drought or high temperatures, where tolerance was quantified as the degree to which biomass is reduced in the presence of drought stress or increased temperature (Strauss et al. 1999; Agrawal et al. 2004; Núñez-Farfán et al. 2007). Genotypes did, however, vary in their ability to avoid wilting (Table 3), as some genotypes began to wilt after 3 days, while others had not wilted after 15 days.

\section{Effects of drought and temperature on plant resistance to herbivores}

On average, drought increased susceptibility (=decreased resistance) of plants to herbivores, where the three caterpillar species gained 16-24\% more biomass on leaves excised from plants that had previously experienced drought than they did on leaves excised from control plants (Fig. 3). This increase in susceptibility was qualitatively consistent across all herbivores and statistically significant for $H$. virescens and H. zea, but not S. exigua (Table 4). By contrast, increasing temperature resulted in an overall decrease in insect biomass of 8-17\% (Table 4). Given that insect growth was assayed on leaf disks at room temperature in the lab, these results show how temperature can affect the physiology and chemistry of leaves to influence a plant's resistance against herbivores (i.e., an indirect effect on herbivores mediated by plants), as opposed to any direct effect of temperature on insect performance which was not the focus of this study. These correlations between temperature and insect biomass were significant for two (H. virescens and $H$. zea) of the three herbivore species (Table 4), but they explained relatively little variation in 
Table 2 ANOVA results from Experiment 2 showing the effects of drought, temperature, and herbivory on plant performance
For each response variable we include results from analysis of variance (ANOVA).

Transformations applied to the data are shown in parentheses. The denominator mean-square (MS) used to estimate $F$-values are denoted by "Error", followed by the MS expression in [ ]. Parentheses denote nested factors. We used fractional denominator degrees of freedoms for some tests and rounded them to the nearest whole number in the table, except in one case noted because of the large contribution of multiple error components

\begin{tabular}{|c|c|c|c|c|}
\hline & $d f$ & SS & $F$ & $P$ \\
\hline \multicolumn{5}{|l|}{ Total biomass } \\
\hline Drought & 1 & $2,454.55$ & 23.23 & 0.040 \\
\hline Error [drought $\times$ trial] & 2 & 213.25 & & \\
\hline Trial & 2 & $1,585.51$ & 7.25 & 0.121 \\
\hline Error [drought $\times$ trial] & 2 & 218.73 & & \\
\hline Temperature & 1 & 0.37 & 0.03 & 0.864 \\
\hline Herbivory & 1 & 123.51 & 9.86 & 0.002 \\
\hline Drought $\times$ herbivory & 1 & 31.20 & 2.49 & 0.118 \\
\hline Drought $\times$ trial & 2 & 218.73 & 8.73 & $<0.001$ \\
\hline Error [error] & 84 & $1,052.57$ & & \\
\hline \multicolumn{5}{|l|}{ Above-ground biomass } \\
\hline Drought & 1 & $1,632.51$ & 19.73 & 0.047 \\
\hline Error [drought $\times$ trial] & 2 & 166.71 & & \\
\hline Trial & 2 & $1,322.23$ & 7.71 & 0.115 \\
\hline Error [drought $\times$ trial] & 2 & 171.47 & & \\
\hline Temperature & 1 & 1.12 & 0.14 & 0.706 \\
\hline Herbivory & 1 & 103.64 & 13.28 & 0.001 \\
\hline Drought $\times$ herbivory & 1 & 27.19 & 3.48 & 0.066 \\
\hline Drought $\times$ trial & 2 & 171.47 & 10.99 & $<0.001$ \\
\hline Error [error] & 84 & 655.55 & & \\
\hline \multicolumn{5}{|l|}{ Below-ground biomass } \\
\hline Drought & 1 & 74.56 & 43.69 & 0.021 \\
\hline Error [drought $\times$ trial] & 2 & 3.49 & & \\
\hline Trial & 1 & 11.07 & 4.37 & 0.125 \\
\hline Error [drought $\times$ trial] & 3 & 7.88 & & \\
\hline Temperature & 1 & 1.31 & 0.6 & 0.494 \\
\hline Herbivory & 1 & 0.38 & 0.22 & 0.687 \\
\hline Chamber [temperature] & 3 & 6.39 & 3.88 & 0.012 \\
\hline Error [drought $\times$ trial] & 2 & 3.59 & & \\
\hline Drought $\times$ trial & 2 & 3.5 & 3.19 & 0.047 \\
\hline Herbivory $\times$ trial & 2 & 3.6 & 3.28 & 0.043 \\
\hline Error [error] & 79 & 43.33 & & \\
\hline \multicolumn{5}{|c|}{ Above-ground:below-ground biomass ratio (log transformed) } \\
\hline Drought & 1 & 0.05 & 0.70 & 0.49 \\
\hline Error [drought $\times$ trial] & 2 & 0.14 & & \\
\hline Trial & 1 & 2.56 & 40.97 & 0.018 \\
\hline Error $[0.81[$ drought $\times$ trial $]+0.19[$ error $]]$ & 2 & 0.14 & & \\
\hline Temperature & 1 & 0.004 & 0.03 & 0.881 \\
\hline Error [chamber (temperature)] & 3 & 0.40 & & \\
\hline Herbivory & 1 & 0.44 & 23.70 & $<0.001$ \\
\hline Chamber [temperature] & 3 & 0.40 & 7.17 & $<0.001$ \\
\hline Drought $\times$ herbivory & 1 & 0.06 & 3.29 & 0.074 \\
\hline Drought $\times$ trial & 2 & 0.14 & 3.90 & 0.024 \\
\hline Drought $\times$ temperature & 1 & 0.04 & 2.34 & 0.130 \\
\hline Error [error] & 79 & 1.47 & & \\
\hline
\end{tabular}

drought treatments, and these results confirm previous findings for specific cultivars. For example, the PI 416937 and breeding line G04-Ben229IR-M, which were previously known to have insect resistance properties (see 

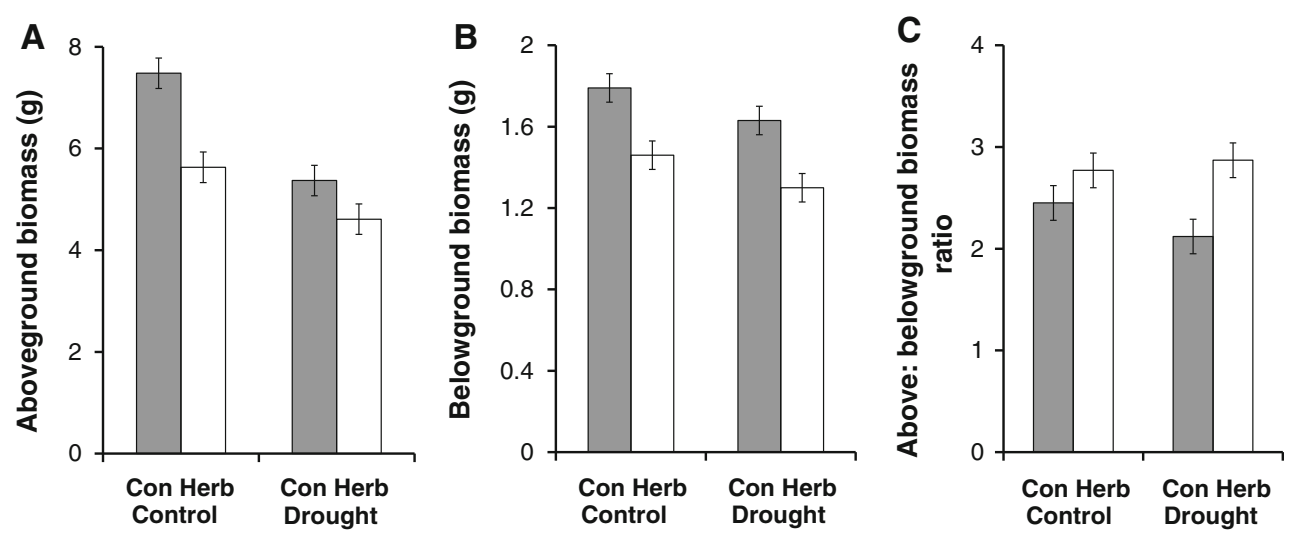

Fig. 1 Effects of drought and herbivory on soybean performance during Experiment 1. We show the combined effects of drought and herbivory on a the above-ground biomass, $\mathbf{b}$ the below-ground biomass, and $\mathbf{c}$ the ratio of the above- to below-ground biomass. Main

Table 3 Results from Experiment 3 on the effects of drought and temperature on the soybean above-ground biomass and wilt avoidance

\begin{tabular}{llrrr}
\hline Explanatory factor & ndf & ddf & $F / \chi^{2}$ & $P$ \\
\hline Above-ground biomass & & & & \\
Drought & 1 & 499 & 11.50 & 0.001 \\
Temperature & 1 & 499 & 0.72 & 0.396 \\
Maturity group & 5 & 499 & 3.89 & 0.005 \\
Temperature $\times$ drought & 1 & 499 & 9.02 & 0.003 \\
Genotype (mat. group) & 1 & & 50.20 & $<0.001$ \\
Wilt avoidance & & & & \\
Temperature & 1 & 199 & 0.06 & 0.80 \\
Maturity group & 5 & 45 & 1.38 & 0.25 \\
Genotype (mat. group) & 1 & & 6.2 & 0.006 \\
\hline
\end{tabular}

The above-ground biomass was measured as the dry biomass of individual plants. Wilt avoidance was measured as the number of days until $>90 \%$ of leaves wilted and the apical meristem was at an angle of $>45^{\circ}$ to the vertical axis. Abbreviations ndf and ddf refer to numerator and denominator degrees of freedom used for $F$ tests, respectively. The effect of genotype was based on a log-likelihood ratio test fit to a $\chi^{2}$ distribution with 1 degree-of-freedom

Online Supplemental Table 1), showed this same attribute in the present study (Kraemer et al. 1988; Zhu et al. 2007). Similarly, two derivatives from PI 416937, slow-wilting N06-7564 and G00-3209, also appeared uniformly resistant. Unexpectedly, cultivars Manokin, Boggs, and N6202 and slow-wilting breeding line N98-7265 were also consistently resistant to caterpillar feeding. Although Manokin and Boggs are resistant to some races of the soybean cyst nematode (Heterodera glycine), neither of these genotypes nor their antecedents have been identified as resistant to foliar feeding insects previously.

Despite the consistency of some genotypes to be insectresistant across drought and control environments, many genotypes interacted strongly with the drought treatment to effects of drought and herbivory are all statistically significant at $P<0.05$, except for the above:below-ground ratio; drought $\times$ herbivory interactions were not significant at $P<0.05$. Detailed results are reported in the text and Table 2

affect resistance (Fig. 3; Table 4). Some plant genotypes showed decreased susceptibility following drought (e.g., soybean aphid-resistant PIs 567301B and 567352B and slowwilting breeding line N05-7462) while still others exhibited increased susceptibility (e.g., soybean aphid-resistant types PI 243540 and Wyandot BC4, aphid-resistant slow-wilting types PI 471931 and Egyptian breeding line H2L16, and cultivar control types Benning and Cook) (Fig. 3).

Within a given treatment (i.e., control or drought), all three herbivore species were significantly positively correlated in their performance across genotypes (control treatment range in r-values: 0.39-0.50, all $P<0.005$; drought treatment range in r-values: $0.38-0.56$, all $P<0.007$ ), indicating that if a soybean genotype was susceptible to one herbivore species, it was typically susceptible to the other herbivore studied. However, the performance of herbivores were not correlated, based on genotypic means, between control and drought treatment $(P>0.1$ for all $r$ values). In other words, the susceptibility of a genotype to $S$. exigua (or the other herbivores) in the control treatment was unrelated to its susceptibility to S. exigua (or a different herbivore species) in the drought treatment. Therefore, for some soybean genotypes, it seems likely that drought stress alters the expression of traits and underlying genes that normally confer resistance to herbivores.

Given that drought changed the susceptibility of many genotypes to herbivores, we sought to identify genetically variable plant traits that predicted the susceptibility to herbivores. Genotypic correlations showed that a genotype's ability to avoid wilting was positively related to its resistance to herbivores (Fig. 4, Online Supplemental Table 2). In other words, plants that avoided wilting tended to be the most resistant to herbivores. Resistance was not strongly correlated with genetic variation in plant growth rate or their ability to tolerate drought, and thus this association between 


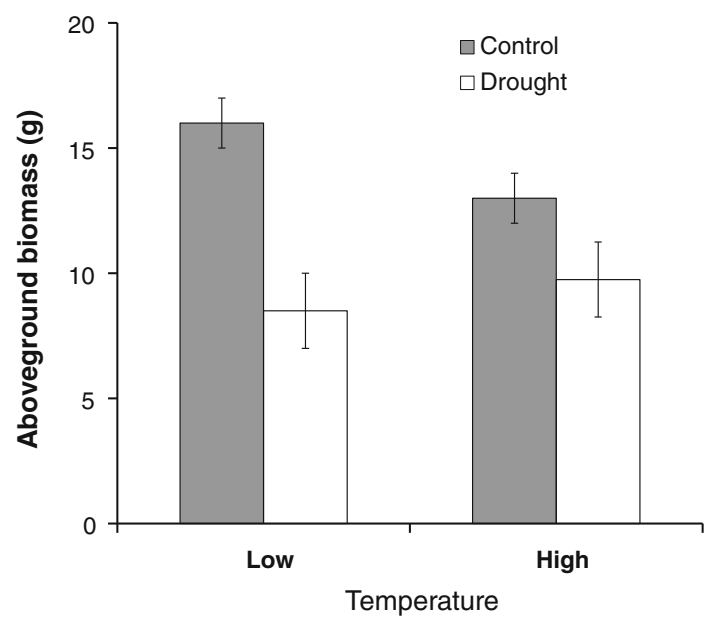

Fig. 2 Interaction between drought and temperature on the aboveground biomass of soybean during Experiment 3. Higher temperatures decreased plant biomass in control plants but had no clear effect on biomass in drought-treated plants. Since temperature varied continuously along a gradient in the greenhouse, we show the predicted mean biomass calculated separately in control and drought treatments from the equation of the line for biomass versus temperature, where "low temperature" represents the predicted mean at the lowest temperature extreme and "high temperature" represents the predicted mean at the highest temperature extreme. The total temperature gradient was $3{ }^{\circ} \mathrm{C}$

wilt avoidance and resistance to herbivores is not likely to be a simple property of larger plants showing faster wilting when grown in pots (Online Supplemental Table 2).

\section{Discussion}

Our experiments provide insight into the interaction of abiotic and biotic stress factors associated with climate change and their influence on plant biomass and plant-herbivore interactions in soybean. Four specific results from our work are the most important in this regard. First, drought and herbivory had consistently strong negative effects on plant performance (Fig. 1, Online Supplemental Fig. 1), but these factors did not strongly interact with one another. Therefore, we find little evidence for synergistic negative effects of multiple stressors. Second, the modest increases $\left(2-3{ }^{\circ} \mathrm{C}\right)$ in temperature had weak negative effects on soybean performance (Fig. 2) and small positive indirect effects on soybean's resistance to herbivores (Table 4). Third, drought tended to decrease resistance of plants to generalist caterpillars, but this effect varied dramatically among soybean genotypes (Fig. 3). Fourth, the ability of soybean to avoid wilting is genotypically correlated with resistance to multiple generalist noctuid herbivores (Fig. 4). As a whole, our results provide insight into how environmental stresses linked to climate change may negatively influence plants.
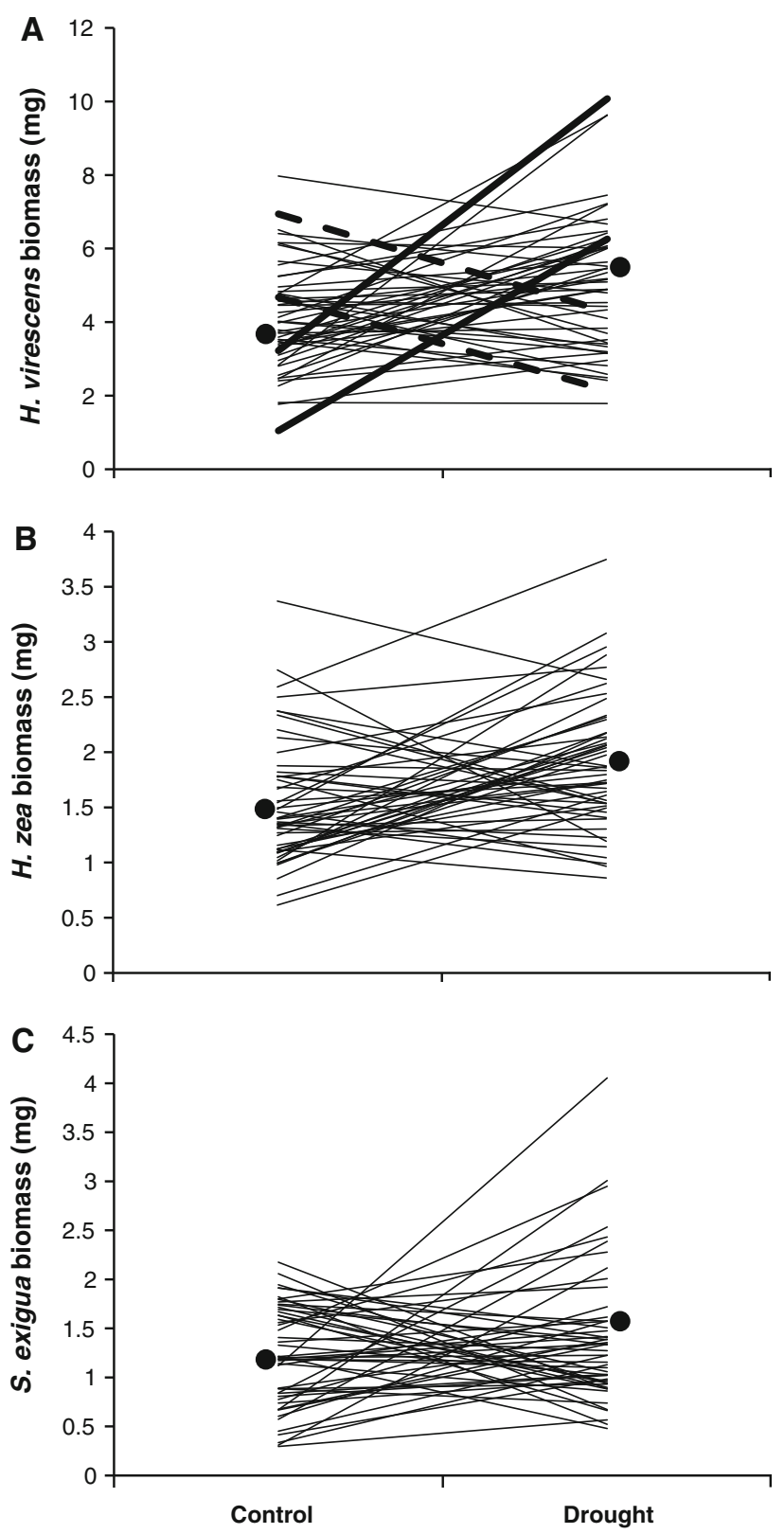

Fig. 3 Reaction norm plots showing the effects of plant genotype and drought on the performance of three insect herbivores during Experiment 3. Plant genotype and drought interacted to affect a Heliothis virescens, b Helicoverpa zea, and c Spodoptera exigua. These figures illustrate large genotypic differences in how drought affects the susceptibility of soybean to generalist herbivores. In each panel, lines depict the norm of reaction for a single genotype in treatments with either continuous watering (control) or plants that experienced drought prior to a no-choice bioassay. In order to depict the range of genotypic responses, a shows two heavy solid lines where two arbitrary soybean genotypes were more susceptible to herbivores on drought-treated plants than control plants, and two heavy dotted lines where two arbitrary genotypes were less susceptible to herbivores on drought-treated plants than control plants. Black circular dots represent the overall mean in control and drought environments 
Table 4 Effects of drought, temperature, maturity group, and plant genotype on insect biomass for three generalist-feeding herbivore species (Experiment 3)

\begin{tabular}{llll}
\hline & $d f$ & $F / \chi^{2}$ & $P$ \\
\hline Heliothis virescens & & & \\
Drought & 1,95 & 9.42 & 0.003 \\
Temperature & 1,366 & 7.66 & 0.006 \\
Maturity group & 5,95 & 0.55 & 0.74 \\
Genotype (maturity group) & 1 & 0.10 & 0.38 \\
Genotype $\times$ drought & 1 & 2.50 & 0.057 \\
Helicoverpa zea & & & \\
Drought & 1,50 & 12.90 & 0.001 \\
Temperature & 1,373 & 10.40 & 0.001 \\
Maturity group & 5,45 & 2.61 & 0.024 \\
Genotype (maturity group) & & 0.10 & 0.376 \\
Genotype $\times$ drought & & 5.90 & 0.008 \\
Spodoptera exigua & & & \\
Drought & & 2.95 & 0.092 \\
Temperature & 1,50 & 0.06 & 0.8 \\
Maturity group & 1,353 & 1.38 & 0.25 \\
Genotype (maturity group) & 0 & 0 & 0.5 \\
Genotype $\times$ drought & 0.016 & 5.20 & 0.011 \\
\hline
\end{tabular}

Insect bioassays were conducted as no-choice feeding assays in which insects were allowed to feed on leaf tissue for 7 days. For each fixed effect we provide the numerator (first number) and denominator (second number) degrees of freedom, whereas the random effect of genotype and Genotype $\times$ Drought were tested using nested loglikelihood ratio tests fit to a $\chi^{2}$ distribution with $1 d f$

Effects of drought, herbivory, and temperature on plant performance

Drought and herbivory had consistent negative effects on plant biomass that were largely independent of one another. Many studies have reported negative impacts of drought (e.g., Hoogenboom et al. 1987; Liu et al. 2003; James et al. 2008) and herbivory (Turnipseed and Kogan 1976; Kamalay et al. 1997; Rypstra and Marshall 2005; Costamagna et al. 2007) on the performance of soybean. Comparatively fewer studies, however, have examined the combined effects of these factors on agricultural plants (Shimada et al. 1992; Hawkes and Sullivan 2001; Huberty and Denno 2004). This is an important problem because the combination of multiple stressors can lead to unpredictable nonadditive effects on the performance of organisms, as has been seen in other environmental contexts and biological systems (Relyea 2003; Darling and Cote 2008; Silva et al. 2010). The results from our factorial experiments show that drought and herbivory did not have synergistic negative effects on plant performance of the soybean variety we used in Experiments 1 and 2. Any interactions between these factors were weak, suggesting that it may be possible to predict the effects of these stressors by studying these
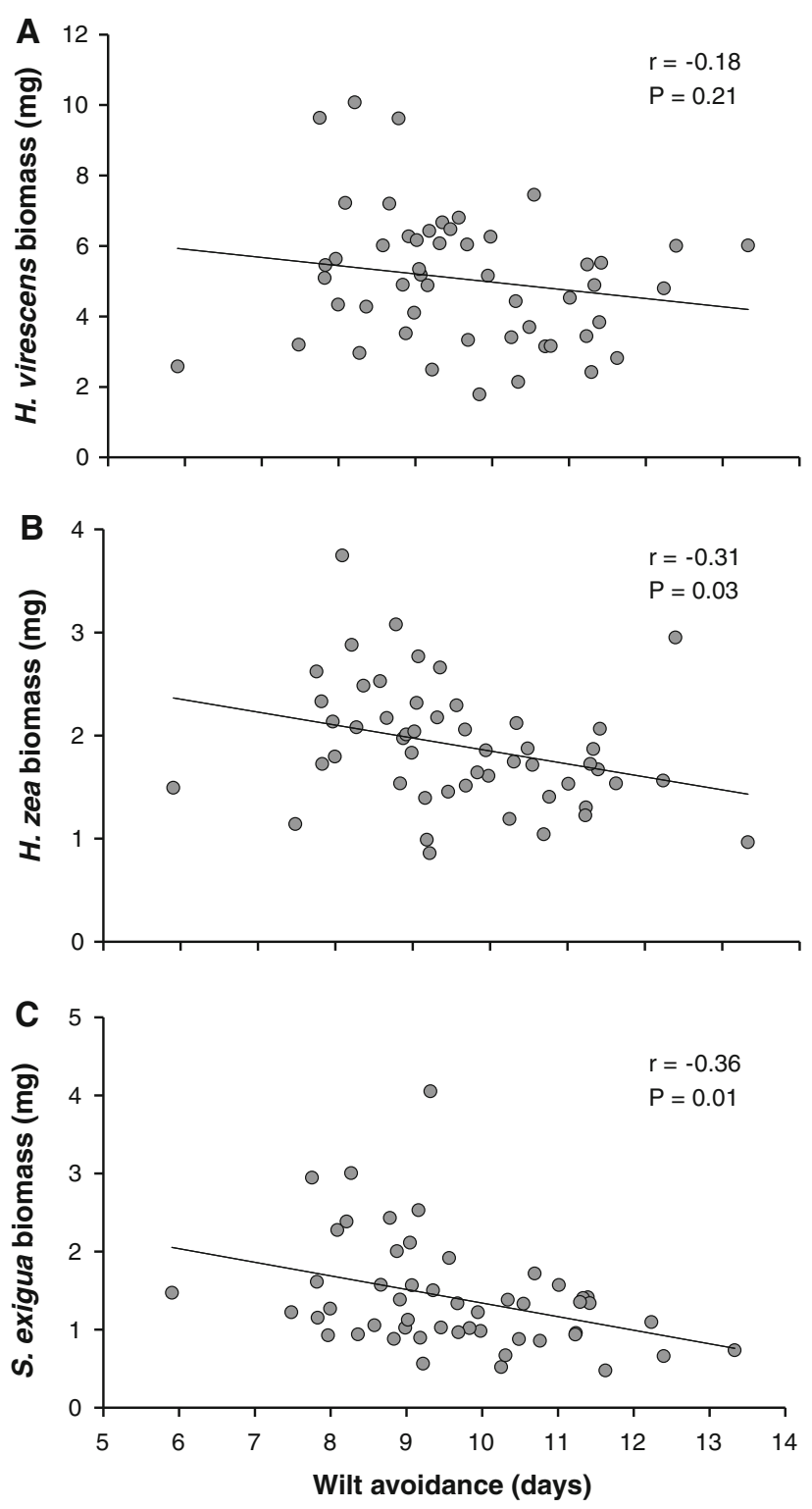

Fig. 4 Genotypic correlations between wilt avoidance and insect performance. We show genotypic correlations between herbivore susceptibility and wilting avoidance for a Heliothis virescens, b Helicoverpa zea, and c Spodoptera exigua. Susceptibility to herbivores was measured as the gain in mass of herbivores during a no-choice bioassay. Wilt avoidance was measured as the number of days until $>90 \%$ of leaves lost turgor and the apical meristem bent over. Each point represents the least-squares genotypic mean of insect biomass and wilt avoidance

factors in isolation. This conclusion is also largely consistent with the results from a meta-analysis of mostly noncrop plants, which examined the combined effects of herbivory and variation in the abiotic environment (water, nutrients, and light) (Hawkes and Sullivan 2001).

Our experiments suggest that the modest increases in temperature $\left(2-3{ }^{\circ} \mathrm{C}\right)$ have little effect on allocation to soybean biomass. The only negative effect of increased 
temperature on soybean biomass was observed in Experiment 3 (Fig. 2), where there was a slightly greater range in temperature than Experiment 2. Even when we observed decreased performance of soybean at higher temperatures, this was dependent on the drought treatment, where higher temperatures were correlated with the modest decreases in the soybean above-ground biomass of well-watered plants while temperature had no detectable effect on biomass of drought-treated plants. These results tentatively suggest that if the target for future temperature increases are limited to $2{ }^{\circ} \mathrm{C}$ (UNFCCC 2009), then increased temperature may have little discernible impact on soybean performance. We hasten to add that observational and manipulative field experiments are needed to confirm this speculation, including its applicability in other agricultural systems.

Effects of drought and temperature on plant defenses against herbivores

Our results have important implications for long-standing predictions relating to the effects of environmental stress on plant defenses against herbivores. The Plant Stress Hypothesis posits that abiotic stress causes plants to become more susceptible to some herbivores (White 1984, 2009). The generality of this hypothesis has been questioned based on the results of two meta-analyses that examined the effects of environmental stress (drought, pollution, and shading) on the preference and performance of multiple insect herbivores from a variety of feeding guilds (Koricheva et al. 1998; Huberty and Denno 2004). Koricheva et al. (1998) showed that the performance of piercing/sucking insects (e.g., aphids) is consistently greater on stressed plants as predicted by the hypothesis, while leaf-chewing insects either showed no response to stress or exhibited decreased performance. Huberty and Denno (2004) also found no clear effect of drought on leafchewing insects, whereas they found variable effects on piercing/sucking insects. They proposed the "Pulsed Stress Hypothesis" based on the observation that continuous drought stress had negative effects on piercing/sucking insects whereas intermittent stress typically had positive effects.

Our results are the most consistent with the Pulsed Stress Hypothesis, but they also provide insight into the context dependency of the effects of drought on plant resistance against herbivores due to plant genetic variation. All three of our herbivore species were generalist-feeding leaf-chewing caterpillars in the Noctuidae, and they were allowed to feed on plant tissue that was recovering from a recent "pulsed" drought. On average, each herbivore exhibited increased performance on previously droughtstressed plants (Fig. 3; Table 4). Our results suggest that the Pulsed Stress Hypothesis may also apply to leafchewing Lepidoptera with generalist diets. This conclusion supports several other recent studies which find increased preference and/or performance of generalist-feeding leafchewing insects on drought-stressed plants (Showler and Moran 2003; Gutbrodt et al. 2011; Mody et al. 2009; Walter et al. 2012). However, when we look more closely, our results on soybean depend completely on plant genotype as we observed all possible effects of the drought treatment on plant susceptibility to herbivores across the 51 genotypes (Fig. 3). This reflects the large genetic variation among soybean genotypes in how drought modifies the expression of resistance to herbivores.

Genotypic correlations between plant drought response and insect performance

Genetic variation in phenotypic traits can have important ecological consequences on species interactions (Leimu and Koricheva 2006a; Whitham et al. 2006; Johnson and Stinchcombe 2007; Carmona et al. 2011) and it is the most important raw material for crop improvement (Sinclair 2011). In the case of soybean, there is an abundance of genotypes (or varieties) available to breeders and farmers. For example, the US Department of Agriculture (USDA) maintains germplasm for over 18,000 accessions of soybean and globally there are over 156,000 accessions (Carter et al. 2004). The current efforts to sequence the soybean genome and transcriptomes from multiple tissues and for many varieties strengthen this system as a model crop as they allow breeders to gain better insight into the genes that correspond to desired traits (Kim et al. 2010; Lam et al. 2010; Wu et al. 2010). In this context, identifying traits that respond to drought and resistance against herbivores is an important avenue for identifying potential traits and germplasm for future breeding efforts (Sinclair 2011).

The observation of positive genotypic correlations in susceptibility across three noctuid caterpillar species suggests that the same pleiotropic and/or linked genetic mechanisms may convey resistance to multiple herbivores (Roche and Fritz 1997; Stinchcombe and Rausher 2001; Leimu and Koricheva 2006a; Johnson and Agrawal 2007). The practical implication of this result is that breeding resistance against one herbivore can potentially help to breed resistance against other herbivores (Kraemer et al. 1988; Carter et al. 2004; Zhu et al. 2006; Zhu et al. 2007). Of particular interest was our finding that plants exhibited significant genetic variation in wilting avoidance, whereby plant genotypes that avoided wilting for longer periods of time also tended to be the most resistant to noctuid caterpillars (Fig. 4). It is not clear whether other arthropod herbivore species more distantly related to the ones studied here, or herbivores that exhibit different feeding habits 
would show similar responses to the genotypes and traits we studied. Nevertheless, our results show that identifying these types of correlations and genotypes that maintain performance under multiple stresses could provide breeders, and eventually farmers, with new varieties that might be better suited for future climates (Carter et al. 2004; Long and Ort 2010; Sinclair 2011).

Evidence from our study suggests that new soybean varieties that combine both insect and drought resistance can be developed. For example, the exotic PI 416937, which exhibits both a slow-wilting trait and insect resistance in the field, has been used as parental stock to develop slow-wilting breeding lines with improved agronomic potential (Carter et al. 1999; Carter et al. 2003; Narvel et al. 2004). Several of these new breeding lines appeared insect-resistant in our study under both severe and minimal stress, even though these new lines were not consciously selected for insect resistance. These new breeding lines may aid in identifying the molecular, physiological, and metabolic mechanisms underlying relationships between drought and insect resistance.

\section{Conclusions and implications}

Multifactor experiments are needed to disentangle the potential additive and non-additive effects of environmental factors on species interactions, especially those related to climate change. This is especially important and urgent in agriculture, where securing food production in the face of both climate change and increasing global population sizes is among the greatest challenge facing our time (Long and Ort 2010; Chin et al. 2011; Lee 2011). Our experimental results support the view that drought and herbivory will be important factors affecting soybean growth and biomass, while the modest increases in temperature $\left(2-3{ }^{\circ} \mathrm{C}\right)$ might be of lesser concern for plants and the insects studied here. Importantly, our results imply that the impacts of drought, temperature, and herbivory on plant performance can largely be understood by studying the independent effects of each stressor, because the multiple stressors studied interacted only weakly and never in a synergistic manner.

Acknowledgments We thank the staff at the NCSU Phytotron and NCSU Method Road Greenhouse Facility who provided logistical support with experiments, especially Janet Shurtleff, Carole Saravitz, and Neal Robertson. Fred Gould supplied Heliothis virescens for Experiments 1 and 2. The USDA-ARS supplied seeds, and additional seed suppliers are identified in Online Supplemental Table 1. Ashley Childress, Diego Carmona, Erika Hersch-Green, Cassi Myburg, Robert San Miguel, and Nash Turley provided assistance with experiments. C. Thomsen provided comments on an earlier draft of the paper. This research was funded by USDA-ARS (TEC), North Carolina State University (RG, MTJJ), an NSERC Discovery grant, the Canadian Foundation for Innovation, and the Ontario Government (MTJJ).

\section{References}

Adams HD, Guardiola-Claramonte M, Barron-Gafford GA, Villegas JC, Breshears DD, Zou CB, Troch PA, Huxman TE (2009) Temperature sensitivity of drought-induced tree mortality portends increased regional die-off under global-change-type drought. Proceed Nat Acad Sci USA 106:7063-7066

Agrawal AA, Conner JK, Johnson MTJ, Wallsgrove R (2002) Ecological genetics of an induced plant defense against herbivores: additive genetic variance and costs of phenotypic plasticity. Evolution 56:2206-2213

Agrawal AA, Conner JK, Stinchcombe JR (2004) Evolution of plant resistance and tolerance to frost damage. Ecol Lett 7:1199-1208

American Soybean Association (2010) Soy Stats. URL: www. soystats.com/2010/Default-frames.htm

Battisti DS, Naylor RL (2009) Historical warnings of future food insecurity with unprecedented seasonal heat. Science 323:240-244

Burton JW, Carter TE (2005) Registration of 'NC-Roy' soybean. Crop Sci 45:2654-26545

Campitelli BE, Simonsen AK, Wolf AR, Manson JS, Stinchcombe JR (2008) Leaf shape variation and herbivore consumption and performance: a case study with Ipomoea hederacea and three generalists. Arthropod-Plant Interact 2:9-19

Carmona D, Lajeunesse MJ, Johnson MTJ (2011) Plant traits that predict resistance to herbivores. Funct Ecol 25:358-367

Carter TE, De Souza PI, Purcell LC (1999) Recent advances in breeding for drought and aluminum resistance in soybean. In: Kauffman H (ed) Proceedings of the world soybean conference VI. Superior Print, Champaign, pp 542

Carter TE Jr, Burton JW, Bowman DT, Cui Z, Zhou X, Villagarcia M, Niewoehner AS, Fountain MO (2003) Registration of 'N7001' soybean. Crop Sci 43:1126-1127

Carter TE Jr, Nelson RL, Sneller C, Cui Z (2004) Genetic diversity in soybean, 3rd edn. American Society of Agronomy, Madison

Charlson DV, Bhatnagar S, King CA, Ray JD, Sneller CH, Carter TE, Purcell LC (2009) Polygenic inheritance of canopy wilting in soybean Glycine max (L.) Merr. Theor Appl Genet 119:587-594

Chin G, Marathe T, Roberts L (2011) Doom or vroom? Science 333:539

Costamagna AC, Landis DA, Difonzo CD (2007) Suppression of soybean aphid by generalist predators results in a trophic cascade in soybeans. Ecol Appl 17:441-451

Cox WJ, Cherney JH (2011) Growth and yield responses of soybean to row spacing and seeding rate. Agron J 103:123-128

Daane KM, Williams LE (2003) Vineyard irrigation amounts to reduce insect pest damage. Ecol Appl 13:1650-1666

Darling ES, Cote IM (2008) Quantifying the evidence for ecological synergies. Ecol Lett 11:1278-1286

Easterling WE, Aggarwal PK, Batima P, Brander KM, Erda L, Howden SM, Kirilenko AP, Morton J, Soussana J-F, Schmidhuber J, Tubiello FN (2007) Food, fibre and forest products. In: Parry ML, Canziani OF, Palutikof JP, Van der Linden PJ, Hanson CE (eds) Climate change 2007: impacts, adaptation and vulnerability. Contribution of working group II to the fourth assessment report of the intergovernmental panel on climate change. Cambridge University Press, Cambridge, pp 273-313

English-Loeb G, Stout MJ, Duffey SS (1997) Drought stress in tomatoes: changes in plant chemistry and potential nonlinear consequences for insect herbivores. Oikos 79:456-468

Fehr WR, Caviness CE (1977) Stages of soybean development, Special report 80, Ames, IA, Extension Services

Fry JD (2004) Chapter 2: estimation of genetic variances and covariances by restricted maximum likelihood using PROC MIXED. In: Saxton AM (ed) Genetic analysis of complex traits using SAS. SAS Institute, Cary 
Geber MA, Griffen LR (2003) Inheritance and natural selection on functional traits. Int J Plant Sci 164:S21-S42

Glynn C, Ronnberg-Wastjung A, Julkunen-Tiitto R, Weih M (2004) Willow genotype, but not drought treatment, affects foliar phenolic concentrations and leaf-beetle resistance. J Chem Ecol 113:1-14

Gutbrodt B, Mody K, Dorn S (2011) Drought changes plant chemistry and causes contrasting responses in lepidopteran herbivores. Oikos 120:1732-1740

Hale BK, Herms DA, Hansen RC, Clausen TP, Arnold D (2005) Effects of drought stress and nutrient availability on dry matter allocation, phenolic glycosides, and rapid induced resistance of poplar to two lymantriid defoliators. J Chem Ecol 31:2601-2620

Hartwig EE (1973) Varietal development. In: Caldwell BE (ed) Soybean: improvement, production, and uses, vol 16. Madison, WI, pp 187-210

Hawkes CV, Sullivan JJ (2001) The impact of herbivory on plants in different resource conditions: a meta-analysis. Ecology 82:2045-2058

Hoffmann AA, Sgro CM (2011) Climate change and evolutionary adaptation. Nature 470:479-485

Hoogenboom G, Huck MG, Peterson CM (1987) Root growth rate of soybean as affected by drought stress. Agron J 79:607-614

Huberty AF, Denno RF (2004) Plant water stress and its consequences for herbivorous insects: a new synthesis. Ecology 85:1383-1398

IPCC (2007) Climate change 2007: synthesis report. Contribution of working groups I, II, and III to the fourth assessment report of the intergovernmental panel on climate change. In: Core Writing Team, Pachauri RK, Reisinger A (eds) IPCC, Geneva, Switzerland, pp 104

James AT, Lawn RJ, Cooper M (2008) Genotypic variation for drought stress response traits in soybean. I. Variation in soybean and wild Glycine spp. for epidermal conductance, osmotic potential, and relative water content. Aust J Agric Res 59: 656-669

Johnson MTJ, Agrawal AA (2005) Plant genotype and environment interact to shape a diverse arthropod community on evening primrose (Oenothera biennis). Ecology 86:874-885

Johnson MTJ, Agrawal AA (2007) Covariation and composition of arthropod species across plant genotypes of evening primrose (Oenothera biennis). Oikos 116:941-956

Johnson MTJ, Stinchcombe JR (2007) An emerging synthesis between community ecology and evolutionary biology. Trends Ecol Evol 22:250-257

Johnson MTJ, Smith SD, Rausher MD (2009) Plant sex and the evolution of plant defenses against herbivores. Proceed Nat Acad Sci USA 106:18079-18084

Kamalay JC, Barger JH, Pierson PE (1997) Survival and development of gypsy moths (Lepidoptera: Lymantriidae) on corn and soybean foliage. J Econ Entomol 90:147-153

Karban R, Baldwin IT (1997) Induced responses to herbivory. University of Chicago Press, Chicago

Kelly AE, Goulden ML (2008) Rapid shifts in plant distribution with recent climate change. Proceed Nat Acad Sci USA 105: $11823-11826$

Kim MY, Lee S, Van K, Kim TH, Jeong SC, Choi IY, Kim DS, Lee YS, Park D, Ma J, Kim WY, Kim BC, Park S, Lee KA, Kim DH, Kim KH, Shin JH, Jang YE, Do Kim K, Liu WX, Chaisan T, Kang YJ, Lee YH, Moon JK, Schmutz J, Jackson SA, Bhak J, Lee SH (2010) Whole-genome sequencing and intensive analysis of the undomesticated soybean (Glycine soja Sieb. and Zucc.) genome. Proceed Nat Acad Sci USA 107:22032-22037

Kogan M, Kuhlman DE (1982) Soybean insects: identification and management in Illinois. University of Illinois, UrbanaChampaign

Kogan M, Turnipseed SG (1987) Ecology and management of soybean arthropods. Ann Rev Entomol 32:507-538
Koricheva J, Larsson S, Haukioja E (1998) Insect performance on experimentally stressed woody plants: a meta-analysis. Ann Rev Entomol 43:195-216

Kraemer ME, Rangappa M, Benepal PS, Mebrahtu T (1988) Field evaluation of soybeans for Mexican Bean Beetle resistance. I. Maturity groups VI, VII, and VIII. Crop Sci 28:497-499

Lam HM, Xu X, Liu X, Chen WB, Yang GH, Wong FL, Li MW, He WM, Qin N, Wang B, Li J, Jian M, Wang JA, Shao GH, Wang J, Sun SSM, Zhang GY (2010) Resequencing of 31 wild and cultivated soybean genomes identifies patterns of genetic diversity and selection. Nat Gen 42:1053-1059

Lee R (2011) The outlook for population growth. Science 333: 569-573

Leimu R, Koricheva J (2006a) A meta-analysis of genetic correlations between plant resistances to multiple enemies. Am Nat 168:E15E37

Leimu R, Koricheva J (2006b) A meta-analysis of tradeoffs between plant tolerance and resistance to herbivores: combining the evidence from ecological and agricultural studies. Oikos 112:1-9

Littell RC, Milliken GA, Stroup WW, Wolfinger RD (1996) SAS system for mixed models. SAS Institute, Cary

Liu FL, Andersen MN, Jensen CR (2003) Loss of pod set caused by drought stress is associated with water status and ABA content of reproductive structures in soybean. Funct Plant Biol 30:271-280

Logan JA, Regniere J, Powell JA (2003) Assessing the impacts of global warming on forest pest dynamics. Front Ecol Environ $1: 130-137$

Long SP, Ort DR (2010) More than taking the heat: crops and global change. Curr Opin Plant Biol 13:241-248

Matson PA, Parton WJ, Power AG, Swift MJ (1997) Agricultural intensification and ecosystem properties. Science 277:504-509

McPherson RM, Wells ML, Bundy CS (2001) Impact of the early soybean production system on arthropod pest populations in Georgia. Environ Entomol 30:76-81

Micinski S, Blouin DC, Waltman WF, Cookson C (2008) Abundance of Helicoverpa zea and Heliothis virescens in pheromone traps during the past twenty years in northwestern Louisiana. Southwest Entomol 33:139-149

Mody K, Eichenberger D, Dorn S (2009) Stress magnitude matters: different intensities of pulsed water stress produce non-monotonic resistance responses of host plants to insect herbivores. Ecol Entomol 34:133-143

Narvel JM, Carter TE Jr, Jakula LR, Bailey MA, Lee SH, Boerma HR (2004) Registration of NC113 soybean mapping population. Crop Sci 44:704-706

Núñez-Farfán J, Fornoni J, Valverde PL (2007) The evolution of resistance and tolerance to herbivores. Ann Rev Ecol Evol Syst 38:541-566

O'Connor MI (2009) Warming strengthens an herbivore-plant interaction. Ecology 90:388-398

Olson DM, Cortesero AM, Rains GC, Potter T, Lewis WJ (2009) Nitrogen and water affect direct and indirect plant systemic induced defense in cotton. Biol Control 49:239-244

Paritsis J, Veblen TT (2011) Dendroecological analysis of defoliator outbreaks on Nothofagus pumilio and their relation to climate variability in the Patagonian Andes. Global Change Biol $17: 239-253$

Parmesan C (2006) Ecological and evolutionary responses to recent climate change. Ann Rev Ecol Evol Syst 37:637-669

Portmann RW, Solomon S, Hegerl GC (2009) Spatial and seasonal patterns in climate change, temperatures, and precipitation across the United States. Proceed Nat Acad Sci USA 106: 7324-7329

Relyea RA (2003) Predator cues and pesticides: a double dose of danger for amphibians. Ecol Appl 13:1515-1521 
Roche BM, Fritz RS (1997) Genetics of resistance of Salix sericea to a diverse community of herbivores. Evolution 51:1490-1498

Rouault G, Candau J-N, Lieutier F, Nageleisen L-M, Martin J-C, Warzee N (2006) Effects of drought and heat on forest insect populations in relation to the 2003 drought in Western Europe. Ann For Sci 63:613-624

Roy BA, Gusewell S, Harte J (2004) Response of plant pathogens and herbivores to a warming experiment. Ecology 85:2570-2581

Rypstra AL, Marshall SD (2005) Augmentation of soil detritus affects the spider community and herbivory in a soybean agroecosystem. Entomol Exp Appl 116:149-157

SAS Institute Inc (2009) SAS/STAT user's guide, 2nd edn. SAS Institute Inc, Cary

Shimada S, Kokubun M, Shibata H, Satsui S (1992) Effect of water supply and defoliation on photosynthesis, transpiration and yield of soybean. Jpn J Crop Sci 61:264-270

Showler AT, Moran PJ (2003) Effects of drought stressed cotton, Gossypium hirsutum L., on beet armyworm, Spodoptera exigua (Hubner), oviposition, and larval feeding preferences and growth. J Chem Ecol 29:1997-2011

Silva EN, Ferreira-Silva SL, Fontenele AD, Ribeiro RV, Viegas RA, Silveira JAG (2010) Photosynthetic changes and protective mechanisms against oxidative damage subjected to isolated and combined drought and heat stresses in Jatropha curcas plants. J Plant Physiol 167:1157-1164

Sinclair TR (2011) Challenges in breeding for yield increase for drought. Trends Plant Sci 16:289-293

Stinchcombe JR, Rausher MD (2001) Diffuse selection on resistance to deer herbivory in the ivy leaf morning glory, Ipomoea hederacea. Am Nat 158:376-388

Strauss SY, Siemens DH, Decher MB, Mitchell-Olds T (1999) Ecological costs of plant resistance to herbivores in the currency of pollination. Evolution 53:1105-1113

Turnipseed SG, Kogan M (1976) Soybean entomology. Ann Rev Entomol 21:247-282

Tylianakis JM, Didham RK, Bascompte J, Wardle DA (2008) Global change and species interactions in terrestrial ecosystems. Ecol Lett 11:1351-1363

UNFCCC (2009) Decision 2/CP.15 Copenhagen Accord pp 4-10. http://unfccc.int/documentation/documents/advanced_search/ items/6911.php?priref $=600005735 \#$ beg

van Mantgem PJ, Stephenson NL, Byrne JC, Daniels LD, Franklin JF, Fule PZ, Harmon ME, Larson AJ, Smith JM, Taylor AH, Veblen TT (2009) Widespread increase of tree mortality rates in the western United States. Science 323:521-524
Walter J, Hein R, Auge H, Beierkuhnlein C, Loeffler S, Reifenrath K, Schaedler M, Weber M, Jentsch A (2012) How do extreme drought and plant community composition affect host plant metabolites and herbivore performance? Arthropod-Plant Interact $6: 15-25$

Walther GR, Post E, Convey P, Menzel A, Parmesan C, Beebee TJC, Fromentin JM, Hoegh-Guldberg O, Bairlein F (2002) Ecological responses to recent climate change. Nature 416:389-395

White TCR (1984) The abundance of invertebrate herbivores in relation to the availability of nitrogen in stressed food plants. Oecologia 63:90-105

White TCR (2009) Plant vigour versus plant stress: a false dichotomy. Oikos 118:807-808

White JW, Hoogenboom G, Kimball BA, Wall GW (2011) Methodologies for simulating impacts of climate change on crop production. Field Crops Res 124:357-368

Whitham TG, Bailey JK, Schweitzer JA, Shuster SM, Bangert RK, LeRoy CJ, Lonsdorf EV, Allan GJ, diFazio SP, Potts BM, Fischer DG, Gehring CA, Lindroth RL, Marks JC, Hart SC, Wimp GM, Wooley SC (2006) A framework for community and ecosystem genetics: from genes to ecosystems. Nat Rev Gen 7:510-523

Williams JW, Jackson ST (2007) Novel climates, no-analog communities, and ecological surprises. Front Ecol Environ 5:475-482

Willis CG, Ruhfel B, Primack RB, Miller-Rushing AJ, Davis CC (2008) Phylogenetic patterns of species loss in Thoreau's woods are driven by climate change. Proceed Nat Acad Sci USA 105:17029-17033

Wu XL, Ren CW, Joshi T, Vuong T, Xu D, Nguyen HT (2010) SNP discovery by high-throughput sequencing in soybean. BMC Genomics 11:469

Zavala JA, Casteel CL, DeLucia EH, Berenbaum MR (2008) Anthropogenic increase in carbon dioxide compromises plant defense against invasive insects. Proceed Nat Acad Sci USA 105:5129-5133

Zhu S, Walker DR, Boerma HR, All JN, Parrott WA (2006) Fine mapping of a major insect resistance QTL in soybean and its interaction with minor resistance QTLs. Crop Sci 46:1094-1099

Zhu S, Walker DR, Warrington CV, Parrott WA, All JN, Wood ED, Boerma HR (2007) Registration of four soybean germplasm lines containing defoliating insect resistance QTLs from PI 229358 introgressed into 'Benning'. J Plant Regist 1:162-163 